\title{
EXPLORING THE ROLE OF DATA ANALYTICS IN ENHANCING THE STUDENT EXPERIENCE
}

\author{
Imaan Faker and Mmaki Jantjies \\ Department of Information Systems, University of the Western Cape \\ Cape Town, South Africa
}

\begin{abstract}
Challenges around ensuring the quality and relevance of higher education institution's (HEI's) will persist globally in the years to come. This is of particular concern in South Africa where HEI graduation rates are still considered low. With the vast amount of data that is being generated by organisations, HEIs are increasingly required to utilize data analytic techniques to improve student experience. Data analytics is about creating valuable meaning out of large and complex datasets. Students generate large amounts of data by accessing information, student support and development as well as other social experiences on campus. This data can ethically be used to improve student experiences. This study explores the necessity of academic and social experience data in being able to enhance students' higher education experiences at a South African university. This quantitative research paper forms part of a long-term study exploring how data analytics can be used to improve student administration to enhance the overall student experience at an HEI in South Africa. Using an online self-administered questionnaire, data was gathered from a small sample of students as part of a pilot study at an HEI to understand the student experiences and use of data at the university. Descriptive statistics were used to analyse data. Results suggest that the use of data analytics is still in its early stages in using such data to gain valuable insights in improving student experiences. This exploratory research further provided an understanding into the student administrative issues that exist and provides a basis for further conversations around what the expectations should be when introducing data analytic technologies are within higher education.
\end{abstract}

\section{KEYWORDS}

Data Analytics, Learning Analytics, Academic Analytics, Higher Education, Student Experience, South Africa

\section{INTRODUCTION AND BACKGROUND TO THE RESEARCH PROBLEM}

Higher education is necessary for the growth of a nation (Akareem \& Hossain, 2016). The attainment of a degree is generally believed to be a currency that can be converted to a labour market value (Kromydas, 2017).

The global population of university graduates in OECD and G20 countries (of which South Africa is included) is expected to nearly double by 2030 and challenges around ensuring the quality and relevance of provision will persist (OECD, 2019). It is therefore vital for higher education institutions (HEIs) to enhance the student experience that help students through completing their degrees.

A higher education challenge that still exists in South Africa is the gap between the number of students who are registered at university and the number of students who graduate each year, known as the graduation rate (DHET, 2019).

While some reasons for this gap may be well recognized such as a lack of funding, other reasons may not be as obvious in certain institutions requiring a need to have a greater understanding of student experiences within higher education. Students write their exams online, use digital libraries to borrow library books without human interferences and make several other administrative enquiries within higher education. This interaction with technology generates large amounts of data that HEIs can use in order to improve the student experience. It is in this light that, data analytics is regarded as having the largest potential impact on higher education (Long \& Siemens, 2011) and is expected to be an integral part of future higher education (Tulasi, 2013). Data analytics is about creating valuable meaning out of large and complex datasets (Ong, 2016). 
Calls to reform the efficiency and quality of HEIs have been ongoing, but due to the massive amounts of data that is being generated, such calls have been increasing in its level of urgency (Long \& Siemens, 2011; Tulasi, 2013). Data analytics can include data collected on students' interaction with university systems such as learning management systems and use it to drive powerful feedback loops in order to identify which tasks students have problems with. Furthermore, it opens up a space to raise awareness of student identities and expectations for the student experience at HEIs in South Africa. Considering the above, the research question posed is in this study is: How can data analytics be used to improve student administration in order to enhance overall student experience?

\section{LITERATURE REVIEW}

\subsection{Defining Data Analytics and its Related Terms: Learning Analytics, and Academic Analytics}

The term analytics has become prevalent in the past decade, but the concept dates back many years from when it emerged in the form of decision support applications in the late 1960's and early 1970's (Watson, 2011). Barneveld, et al. (2012) has found that the description of analytics remains consistent irrespective of whether it is used in corporate or academic setting: Analytics is an overall concept to describe data-driven decision making. This entails collecting and analysing data to provide actionable information to decision makers that could steer the strategic direction of their institution (Long \& Siemens, 2011; van Barneveld, Arnold \& Campbell, 2012). The increased use of the internet and mobile technologies have added to the exponential growth in amounts of data. Hence data analytics is being commonly referred to as big data analytics in the same breath because there is a lot of overlap. Both are needed to collect and manage large amounts of data (which is big data) and tools are used to turn that data insight into action (data analytics). Jadhav (2017) combines these two terms into a single simple explanation: Big Data Analytics is the process of investigating large amounts of data to uncover patterns and other needed information.

The large amounts of data that are being generated in several sectors has led to efforts in providing research that is less general and more applicable for certain industry sectors. Hence, there has been varying definitions of what data analytics means in the context of higher education. In this sector, data analytics is widely accepted to comprise two broad sectors, namely Learning Analytics and Academic Analytics (Siemens, et al., 2011; Barneveld, et al., 2012; Daniel, 2015). Learning Analytics is the measurement, collection, analysis and reporting of data about learners and their contexts, for reasons of understanding and enhancing learning and the environments in which it occurs (Siemens, et al., 2011). On the other hand, Academic Analytics is the use of indicators (historical or real-time through dashboards) by management of how the business (the HEI) and its units (colleges, schools, or departments) are performing (Barneveld, et al., 2012). Collectively, both these spheres of data analytics in the setting of higher education leverage data connected with the learning environment in order to assess strategic decision making in relation to academic programs and the student experience (Olocco, 2017). The next sections will explain how the use of these concepts of data analytics, academic analytics and learning analytics has been applied in higher education.

\subsection{Data Analytics and its Applications in Global Higher Education}

By seeing what benefits data analytics can provide for other sectors, higher education institutions (HEIs) are seeing what benefits it can reap for the education sector. Luan (2004) illustrates the higher education equivalents of critical business questions which is provided in Table 1 below. For instance, a business may ask "Who are my repeat website visitors?" whereas academia may ask "Which students are most likely to return for more classes?". Barneveld, et al. (2012) also largely advocates for the benefits of applying data analytic practices in higher education by maintaining that HEIs are taking on organizational success at all levels just like businesses do; through tacking questions of retention, admissions, fund raising, and operational efficiency. 
Table 1. Higher education equivalents of critical business questions (Source: Luan, 2004)

\begin{tabular}{|l|l|}
\hline Private sector questions & Higher education equivalents \\
\hline Who are my most profitable customers? & Which students are taking the most credit hours? \\
\hline Who are my repeat Web site visitors? & Which students are most likely to return for more classes? \\
\hline Who are my loyal customers? & Who are the "persisters" at my university/college? \\
\hline Who is likely to increase his/her purchases? & Which alumni are likely to make larger donations? \\
\hline Which customers are likely to defect to competitors? & What types of courses will attract more students? \\
\hline
\end{tabular}

There have been many initiatives focused on the use of data analytics in higher education largely in the global north. Campbell (2007) devotes an article to describe different initiatives that have been used to predict which students are in academic difficulty using academic analytics. Similarly, Ong (2016) provides a summary of eleven JISC (Joint Information Systems Committee) projects which utilised data analytics to improve higher education in the United Kingdom. Among many uses, some institutions have used analytics to measure the chance of student advancement through courses and majors. For example, Stanford University has undertaken the Open Learning Initiative to improve effectiveness during lectures through student learning data that is collected and reported back to the lecturer (Stanford University, 2018). The system can generate which learning objectives the students are comfortable and not comfortable with based on interactions by the students. The system can also show how much students and which students have particularly not done enough work in the system for the system to make any kind of prediction. Such analytics can provide lecturers with a plethora of useful information such as helping to make judgements about whether students will be prepared for an upcoming test or not. Other institutions have employed data analytics to provide more personalized approaches to advising. For example, Austin Community College (Texas, USA) have identified curriculum advising as being a major issue student struggle with. As a result, they deployed Degree Map, an action analytics application specifically intended to uplift advising discussions by offering a clear outline of a students' degree progress and their remaining years at the institution. The application tells students where they are in their journey, and based on where they are, the next set of courses they should take, and the choices they can make based on changes to majors. It was found that students who engaged with the app to plan their degrees continued their studies at a higher rate than those that did not engage with the app (EdSurge Inc., 2018). Interest of how data analytics can be used to make informed decisions to enhance student experience have therefore increased as part of the solution to many issues in higher education.

\subsection{Data Analytics and its Application in South Africa}

The importance of the use of data analytics has certainly been gaining momentum within South African HEIs. Through two national-level projects funded by the Kresge Foundation, the University of the Free State is developing its analytic capabilities to better understand students and improve assistance in navigating through studies. One example of how they are doing this is by developing academic advising that helps students match their studies with their career and life goals. A study undertaken by Mlangeni (2015) at The Cape Peninsula University of Technology in Cape Town has found that data analytics can assist management with decision-making and predicting the future $99 \%$ accurately based on the data of previous performance. Mlangeni (2015) explains that data analytics is being used to extract valuable information such as those related to the demographic profiling of students as well as course capacities within the institution. Lourens \& Bleazard (2016), Jordaan \& Merwe (2015) as well as Lemmens \& Henn (2016) make their contribution to the rise of data analytics in higher education by focusing on how the use of learning analytics can collect data while students are learning and consequently identify potentially at-risk students with the ability to excel.

\subsection{Method for the Study}

This study made use of a questionnaire that was informed by the research question, the objectives as well as the literature review. The sample population was a small sample of students within a higher educational institution. The first section sought study demographic questions relevant for reporting about university 
students. The second section was about the access to information on campus, in order to understand how students', leave behind their electronic footprint that could possibly be used for data analytic purposes. The third section was about identifying how students are connected with the information services they use to gauge insights as to how it happens. The last section gauged the overall student experience attitude of students at the institution and allowed the opportunity to voice opinions not covered previously to uncover any challenges that are hindering the university experience of students. A total of 45 questions had been asked.

Dillman's (2000) set of design principles for web-based questionnaires were used to construct the questionnaire. Additionally, Neumans' (2014) book section on Survey Research was consulted to ensure the questionnaire complies with best practice for compiling questionnairs.

Data collection took place in two phases. Following approval to conduct the research, a simple random sampling approach was employed where students were approached on campus to be invited to complete the online questionnaire via a link sent to their student email address. This study thus reports initial finding of the exploratory study that forms part of an initial phase of a longitudinal study. Descriptive Statistics was used to describe the results from the small sample study. Narkhede (2018) explains that descriptive statistics pursues the describing of data, and not the inference of data from the sample to the whole population, as is the case with inferential statistics. Therefore results were analysed based on what was explicitly stated and provided by respondents because the response rate $(27 \%)$ was not large enough to make inferences to apply to the whole student population at an HEI. Thematic analysis was employed to analyse open-ended questions that probed for more information from quantitative questions.

\section{RESEARCH RESULTS AND DISCUSSIONS}

\subsection{Profile of the Students}

The study was conducted in a university with a small sample of 27 students partaking in this initial exploratory study. Respondents came from various faculty backgrounds including law, natural science, community \& health, education; and most participants were registered in the economic and management faculty $(74 \%)$. The respondents included both undergraduate $(41 \%)$ and postgraduate experiences $(59 \%)$. The gender ratio in the study was $33 \%$ male and $67 \%$ female. Respondents' age was spread across all age groups, with most of them being between the age of 22-24 (37\%). Lastly, the survey results indicate that none of the respondents have disabilities and it can therefore be said that this study does not extend to those with disabilities.

\subsection{Access to Information Experience}

Most respondents (70\%) believe that it is easy to access the computers on campus from the computer labs made available to students. The $30 \%$ of respondents who did not believe that it was easy to access, attributed this lack of ease to the volume of computers available to students when they need them, indicating that the computers are often reserved by other students or computer rooms are being used for a lecture.

The majority of respondents $(70 \%)$ think that the HEI website is easy to navigate through. However, when asked what students particularly visit the HEI website for, it was found that to a large extent the website is used as a gateway to easily access the library website and the Learning Management System (the university's platform to obtain coursework). Thereafter the website was found to be used to obtain general university dates such as semester dates and exam dates (the academic calendar). This means that the content made available on the HEI website itself is not utilised much by the students. It also suggests that content around general university dates on the website are seen to be important to students. 
The $30 \%$ of respondents who did not believe that it is easy to navigate the HEI website, attributed this to user experience, particularly around how the wealth of information is structured for a student user to find and read it. Three respondents particularly pointed out that there are too many links that are either not updated or do not navigate to what the user is seeking. A participant stated:

\begin{abstract}
"There are too many links/tabs to look at all or go through all at once on the site.Its as if the site is tailored for for alumni's or a older group of people and does not speak to a youth image of students. The site is not only loaded graphically but its distracting and feels heavy to use when seeking simple things. All things useful to students or prospective students are "hidden" and aren't easy to find unless you search and download the pdf. Such as the academic calendar, course rules and module infomation etc... Overall it just feels too cluttered and this makes navigation hard."
\end{abstract}

The above, in addition to the respondents indicating that they use a desktop computer (59\%) more than a cell phone $(37 \%)$ to obtain university-related information, suggests that there is a need to optimize desktop views as students are willing to take their time to read through university information. The above also suggests the need to re-evaluate user experience on the university website (and address business equivalent questions as mentioned in the literature review) to improve students' access to administration information.

Respondents were also asked about the extent that they use common social media platforms to access university-related information. Between Facebook, WhatsApp and Twitter, Twitter starkly stood out as being the platform never used at all to acquire university-related information (56\%). Consequently, Facebook and WhatsApp were found to be most used. On Facebook, the institution has several groups with varying sizes including a buying textbook group, an alumni group, a careers page, and so forth. Because this online platform is often used by students, the use of data analytics for such a platform should be heightened, especially considering that are already tools out there to help with this (e.g. Facebook Analytics application for group and page managing). Facebook can provide several insights that are automatically summarised such as similar pages to watch and compare performance with, amount of views, amount of likes, and amount of students who actually engage instead of merely viewing a post. In this way, admins of HEI Facebook pages and groups do not solely dump their information on the platform but actively engage in the use of analytics to determine the actual value created by it for its students. These groups and pages should be integrated and promoted across each other to increase the chances of a student seeing these groups and joining them. For example, a first-year student may be looking for a textbook in the first year group but may not know that there is a separate page on Facebook for the buying and selling of textbooks.

For this section, respondents were finally asked whether they had wished they had any specific university-related information that was made easier to access via the internet or other mobile means. Responses varied for this question, however there is a persistent theme of student administration that comes through, with phrases used such as "Proof of registration", "faculty administration" and "academic requirement ebook".

\title{
3.3 Student Support and Development
}

Respondents were given a 1-5 rating scale to indicate how helpful they believe the staff in their faculty are. 21 of the 27 respondents $(78 \%)$ indicated that their faculty staff members are between the "extremely helpful" and "neutrally helpful" realms. This correlates with the results of a next question which found that the majority of students feel comfortable speaking to their lecturers. The mean value given for this question was 4, with 1 being "very uncomfortable" at all and 5 being "very comfortable".

Results were almost levelled when asked about the ease of obtaining information on course and qualification content e.g. promotion rules, program registered for such as credits and modules required to pass the year. $44 \%$ indicated that it was not easy, and $56 \%$ indicated that it was easy. This makes sense considering that respondents indicated that they visit the website to access the student portal which makes this information available. In relation to this, $63 \%$ of respondents has had to add and delete modules throughout their university career, and $63 \%$ of respondents have not had good experiences with this. This relates to the previous section which mentions that a theme of student administration came through when students were asked which university-related information they wished were made easier for them to access via the internet or other mobile means. 
If students feel very comfortable speaking to lecturers yet are still experiencing difficulties when it comes to course administration, it means that there is grey area when it comes to the advising on information before a student has registered and their student portal information is available to them (such as the module credits they have for the year). Respondents were vocal on this, and an overall theme of confusion around accessing such information arose. Responses included:

"It's hard to find someone in your faculty that can answer a question like this. They are always sending you to different people for an answer. There is nothing available online that is clear and easy to read as well".

“... the people helping you register don't talk one language. They tell you one thing then after a semester they change their whole sentence and blame you for not knowing things or being aware of changes to your program.",

Based on the above, there exists a lack of clear guidelines as to what students should do and who to see when they have such queries. If a student receives a more accurate and hands-on approach to curriculum advising, the student will be more likely to complete the degree within its stipulated completion time. The literature review section of this article has provided examples of how data analytics has helped university students, through proper curriculum advising, to match their studies with their career and life goals (e.g. the Degree Map application used at Austin Community College). HEI's in South Africa needs such interventions for improved advising of course qualification and content, both online and in person.

\section{CONCLUSION}

Undoubtedly, data analytics has a significant role to play in the future of higher education. This quantitative study explored how data analytics can be used to enhance overall student experience at a higher education institution (HEI) in South Africa. The study found that data from students was not being effectively used to improve student learning and university administration experiences. The reflections from the students provided insight into the current lack of effective use of data driven systems to help improve students experiences across higher education. The study further reflected the lack of integrated use of student data from different sources such as the learning management system in order to personalise learning experiences. Furthermore, this exploratory research provided a glimpse into the student administrative issues that students experience and provides a basis for further conversations around what the expectations of data analytic technologies are within higher education. The limitations of this study are that the research was conducted at a single location with a response rate that is not large enough to firmly generalise the data. The study however concluded on the key role of data collected in helping to improve study experience across higher educational institutions.

\section{REFERENCES}

Akareem, H. S. \& Hossain, S. S., 2016. Determinants of education quality: what makes students' perception different?. Open Review of Educational Research, 3(1), pp. 52-67.

Balkissoon, D., 2016. Thematic Analysis | Design Research Techniques. [Online] Available at: http://designresearchtechniques.com/casestudies/thematic-analysis/ [Accessed 14 August 2018].

Barneveld, A. V., Arnold, K. E. \& Campbell, J. P., 2012. Analytics in Higher Education: Establishing a Common Language. Educause Learning Initiative, Volume 1, pp. 2-11.

Campbell, J. P., DeBlois, P. B. \& Oblinger, D. G., 2007. Academic Analytics: A New Tool for a New Era. EDUCAUSE Review, 42(4), pp. 40-57.

Centre for Education Policy Development (CEPD) Information Booklet, 2010. Stakeholder Summit on Higher Education Transformation, Cape Town: Cape Peninsula University of Technology.

Daniel, B., 2015. Big Data and analytics in higher education:. British Journal of Educational Technology, 46(5), pp. 904-920. 
DHET, 2019. Post-School Education and Training Monitor: Macro-Indicator Trends, South Africa: Department: Higher Education and Training.

Dillman, D. A., 2000. Mail and Internet Surveys: The tailored Design Method. 2 ed. New York: Wiley.

Dominguez-Whitehead, Y., 2017. Non-academic support services and university student. Studies in Higher Education, 43(9), p. 1692-1706.

EdSurge Inc., 2018. Austin Community College - Degree Map. [Online] Available at: https://www.edsurge.com/product-reviews/student-success-platform/company-case-studies/austincommunity-college [Accessed 7 October 2018].

Jadhav, R., 2017. A Review of Big Data Analytics in Sector of Higher Education. International Journal of Engineering Research and Application, 7(6), pp. 25-32.

Jordaan, D. \& van der Merwe, A., 2015. Best practices for learning analytics initiatives in higher education. Moving beyond the hype: A contextualised view of learning with technology in higher education, November, p. 53-58.

Kromydas, T., 2017. Rethinking higher education and its relationship with social inequalities: past knowledge, present state and future potential. Palgrave Communications, 3(1), pp. 1-12.

Lemmens, J. C. \& Henn, M., 2016. Learning Analytics: A South African Higher Education Perspective. Institutional Research in South African Higher Education, 1(12), pp. 231-254.

Long, P. \& Siemens, G., 2011. Penetrating the Fog: Analytics in Learning and Education. EDUCAUSE review, 46(5), pp. 30-41.

Lourens, A. \& Bleazard, D., 2016. Applying predictive analytics in identifying students at risk: A case study. South African Journal of Higher Education, 30(2), pp. 129-142.

Luan, J., 2004. Data Mining Applications in Higher Education, s.l.: SPSS Executive Report (DMHEWP-1004).

Mlangeni, T. C., 2015. Analysis of data governance in higher education institutions : case of a university of technology in South Africa, Cape Town: Cape Peninsula University of Technology Electronic Theses \& Dissertations.

Narkhede, S., 2018. Understanding Descriptive Statistics. $\quad$ [Online] Available at: https://towardsdatascience.com/understanding-descriptive-statistics-c9c2b0641291 [Accessed 7 October 2018].

Neuman, W. L., 2014. Social Research Methods: Qualitative and Quantitative Approaches. 7 ed. Essex, United Kingdom: Pearson Education Limited.

OECD, 2019. Benchmarking Higher Education System Performance, Paris: OECD Publishing.

Olocco, V., 2017. Is Big Data Analytics the solution to Higher Education problems?. [Online] Available https://www.researchgate.net/publication/316974143_Is_Big_Data_Analytics_the_solution_to_Higher_Education_pr oblems[Accessed 2015 September 2018].

Ong, V. K., 2016. Business Intelligence and Big Data Analytics for Higher Education: Cases from UK Higher Education Institutions. Information Engineering Express, 2(1), p. 65 - 75.

Siemens, G. et al., 2011. Open Learning Analytics: An integrated \& modularized platform, Edmonton, Canada: Society for Learning Analytics Research.

Stanford University, 2018. Teach $\quad$ with $\quad$ OLI. Available at: http://oli.stanford.edu/teach-with-oli/ [Accessed 7 October 2018].

Tulasi, B. (2013). Significance of Big Data and Analytics in Higher Education. International Journal of Computer Applications, 68(14), 21-23.

Watson, H. J., 2011. Business Analytics Insight: Hype or here to stay?. Business Intelligence Journal, 16(1), pp. 4-8. 